\title{
Late diagnosis and HIV infection in children attending a service of specialized care for pediatric AIDS in Brazil
}

\author{
Carolina Frizzera Dias ${ }^{[1]}$, Sandra Fagundes Moreira-Silva ${ }^{[1]}$, Marcela Alice Reis ${ }^{[1]}$, \\ Luciana Ribeiro Patrício[1], Camila Fátima Biancardi Gavioli ${ }^{[1]}$ \\ and Angélica Espinosa Miranda ${ }^{[1]}$
}

[1]. Núcleo de Doenças Infecciosas, Universidade Federal do Espírito Santo, Vitória, ES.

\begin{abstract}
Introduction: This study describes the frequency of late diagnosis and HIV among children attending a pediatric AIDS clinic. Methods: Cross-sectional study in children exposed to HIV from 2005-2008. A questionnaire was given that included questions on demographics and clinical information. Results: Two-hundred twenty-one $(97.8 \%)$ children were exposed to HIV during pregnancy/childbirth. A total of $193(87.3 \%)$ children had late enrolment in the service and late access to HIV serology. The frequency of HIV was $21.3 \%$ (95\% confidence interval [CI] 15.9\%-26.7\%). Protective factors were earlier diagnosis [odds ratio $(\mathrm{OR})=0.17(0.08-0.37)]$ and receiving complete prophylaxis $[\mathrm{OR}=0.29(0.09-0.97)]$; being born by vaginal delivery was a risk factor $[\mathrm{OR}=4.45(1.47-13.47)]$. Conclusions: There was a high frequency of late diagnosis in this patient cohort. Earlier diagnosis is an important measure for controlling HIV among children.
\end{abstract}

Keywords: HIV. AIDS. Children. Late diagnosis.

The majority of new cases of HIV-infected children below 5 years old worldwide are either from maternal-infant transmission in utero or occur during labor and delivery or through breastfeeding ${ }^{1}$. Since the study of Connors et al. ${ }^{2}$ showing a $67 \%$ reduction in the risk of human immunodeficiency virus (HIV) maternal-to-child transmission (MTCT) by offering zidovudine to women during pregnancy and childbirth and to the newborns for 6 weeks, it became clear that the MTCT of HIV could be reduced to levels as low as $1 \%$ with the use of combined antiretroviral therapy and cesarean sections ${ }^{2,3}$.

The main indicator for monitoring HIV infection in children is the incidence rate of acquired immunodeficiency syndrome (AIDS) in children under 5 years old. This rate is used as a proxy for the rate of MTCT because it represents almost $90 \%$ of all cases $^{4}$. From 1996 through June 2010, 19,203 cases of AIDS in children below 13 years of age were identified in Brazil, representing 3.2\% of all AIDS cases. Of those, 12,824 (66.8\%) of cases occurred through MTCT. There was a $36.6 \%$ reduction in the incidence of AIDS in children under 5 years from 1999 to 2009. The Southeast, South and Midwest of Brazil experienced decreases in incidence during this period, while the North and Northeast regions experienced increases ${ }^{4}$.

The clinical course of AIDS is faster in children than in adults. This difference is likely due to the poor development of

Address to: Dra. Angelica Espinosa Miranda. Núcleo de Doenças Infecciosas/ UFES. Avenida Marechal Campos 1468, Maruípe, 29040-091 Vitória, ES, Brasil.

Phone: 5527 3335-7210; Fax: 5527 3335-7504

e-mail: espinosa@ndi.ufes.br

Received 7 August 2012

Accepted 23 October 2012 the immune system in children ${ }^{5}$. The diagnosis of AIDS in children is a challenge because the clinical manifestations resemble many other common childhood illnesses, including prolonged or recurrent fever, chronic or recurrent diarrhea, generalized lymphadenopathy, persistent or chronic cough, repetitive upper respiratory tract infections including sinusitis and otitis, recurrent pneumonia, persistent oral candidiasis, ponderal-stature deficit, skin lesions especially eczema, hepatosplenomegaly and delayed neuropsycomotor development ${ }^{6}$.

Early diagnosis of HIV infection in children born to seropositive mothers detected before or during pregnancy or at delivery and to those presenting with nonspecific constitutional symptoms requiring medical care determines the prognoses of these children ${ }^{7}$. The objective of this study was to determine the frequency of HIV infection and late diagnosis in children attending a Service of Specialized Care (SSC) for pediatric AIDS at the State Children's Hospital in Vitória, Brazil.

This report describes a cross-sectional study of children exposed to HIV infection through MTCT; subjects were attendees of the SSC for Pediatric AIDS in Vitória from January 2005 through December 2008.

Data collection was performed in 2010 using a standard questionnaire specific for extracting data from medical records and was supplemented by information from parents or legal guardians. All files for children exposed to HIV infection who were treated from 2005 to 2008 were reviewed and analyzed. Only children exposed to HIV infection by MTCT were included in the study.

The questionnaire used was validated during a pre-test and contained questions about the clinical status of the mother (prenatal care, AIDS Clinical Trials Group [ACTG] protocol in 
pregnancy, labor and delivery/or newborn, ruptured of amniotic membranes, mode of delivery and maternal breastfeeding) and of the children (age at admission into the SSC, gender, skin color, maternal breastfeeding, opportunistic diseases and all results of laboratory tests for HIV). A child was considered HIV-positive when they had a positive HIV test after 18 months of follow-up.

Statistical analysis was performed using SPSS Inc. 17.0 (Windows \& Mac) (Statistical Package for the Social Sciences, Chicago, IL). A descriptive analysis was initially performed, including frequency distributions for the qualitative variables and calculation of medians and interquartile ranges for the quantitative variables. A Chi-square test with Yates correction was used to search for possible associations between clinical, demographic or risk behavior variables and HIV infection. Fisher's exact test was applied when appropriate. Comparisons between HIV-positive and HIV-negative children were tested using odds ratios (ORs) and their 95\% confidence intervals (95\% CIs) to estimate the degrees of association between the diagnosis of HIV infection in the children and potential risk factors. Multivariate logistic regression analysis was used to assess the effect of one variable while controlling the effect of the other.

This study was submitted and approved by the Ethics Committee for Research of the State Children's Hospital.

In total, 226 children were reported to be exposed to HIV from January 2005 through December 2008. Of these, 5 children were excluded ( 3 children were infected through sexual intercourse, and the mode of infection was not identified in the other 2 children). Of the 221 (97.8\%) children exposed to HIV through MTCT, 114 (51.6\%) were male and 107 (48.4\%) female. A total of 47 children became infected with HIV during the study period, resulting in a prevalence of $21.3 \%(95 \%$ CI: $15.9 \%-26.7 \%)$.

A total of $193(87.3 \%)$ children were enrolled late in the service and had late access to HIV serology (after the first year of life), $97.1 \%$ versus $51.1 \%(\mathrm{p}<0.001)$ when comparing the children with AIDS to those that developed negative serology. Fifteen children (6.8\%) died; 9 (60\%) deaths were from AIDSrelated complications among the HIV-infected children, and $6(40 \%)$ deaths from other causes among the uninfected children.

Regarding HIV infection in the mothers of the exposed children, 97 (43.3\%) were diagnosed before pregnancy, $56(25 \%)$ during the prenatal period and $59(26.4 \%)$ at or after delivery. In 12 (5.4\%) cases, the mode of infection was unknown. Clinical data for the mothers are shown in Table 1. All variables studied were associated with HIV infection, except rupture of the amniotic membranes more than 4 hours.

Table 2 displays the factors that were independently associated with HIV infection in children. Protective factors were: having access HIV serology testing before the first year of life $[\mathrm{OR}=0.17$ ( 0.08 to 0.37 )] and having complete prophylaxis $[\mathrm{OR}=0.29(0.09$ to 0.97$)]$. Birth by vaginal delivery $[\mathrm{OR}=4.45$ (1.47 to 13.47)] was a risk factor for HIV infection.

The clinical manifestations were classified according to the clinical criteria of severity (mild and moderate/severe) in children diagnosed with AIDS at the SSC for Pediatric AIDS.
The most prevalent manifestation was anemia for longer than 30 days (62\%). Wasting syndrome (56\%) and bacterial meningitis, pneumonia or sepsis (54\%) were other clinical manifestations. In total, $32 \%$ of cases were classified as category $\mathrm{C} 3$, the most serious category.

In this study, a high frequency of HIV infection in children was observed in the pediatric AIDS care service (21\%). The high frequency can be explained by delayed diagnosis of exposure/HIV infection (87.3\%), which precluded the adoption of prevention measures. In our study, early diagnosis and the initiation of medical follow-up of these children soon after birth were protective factors.

Despite free access to antiretroviral therapy (ART) in Brazil, many HIV-infected pregnant women do not benefit from the preventive measures recommended by the Ministry of Health ${ }^{3}$. The women do not get the anti-HIV test because of either their social status or discrepancies in the health system. The late detection of HIV infection during prenatal care represents a missed opportunity for interventions in infected pregnant women. This delay limits the possibilities for reducing the incidence of pediatric $\mathrm{HIV}$ cases from $\mathrm{MTCT}^{8}$, as it makes MTCT more likely and results in more severe clinical manifestations in children.

Maternal-to-child transmission of HIV is the main cause of new infections in children. Some studies conducted in Brazil assessing the frequency of MTCT differed in the rates of infection in children, with the incidence ranging from 2.8 to $9.9 \%^{8-13}$. Despite the free access to ART in Brazil, MTCT is not under control. These data show the importance of early screening for HIV during prenatal care to reduce the number of HIV cases in children. Earlier diagnosis of HIV infection in a mother allows for greater chances of avoiding infection of the newborn.

The incidence of women receiving prenatal care was high $(80.5 \%)$ in this study. Of those mothers who received prenatal care, $150(86.2 \%)$ newborns were not HIV-infected. Among the mothers who had not received prenatal care, the probability of HIV infection in newborns was three times higher, though this finding was not statistically significant. In Brazil, prenatal care rates are high $(>90 \%)$, but not all pregnant women are tested for $\mathrm{HIV}$, and the opportunity for treatment is missed ${ }^{8,14}$.

The majority of the mothers of the children attending the SSC for Pediatric AIDS knew they were infected with HIV prior to pregnancy or discovered they were infected with the virus during pregnancy. These results are similar to previous studies conducted in other cities in Brazil ${ }^{10,11,14}$. Succi et al. ${ }^{10}$ observed similar findings in a multicenter study conducted in Brazil in 2000 and 2001, though those patients had lower rates of $\mathrm{MTCT}^{10}$. The application of the full recommendation is a protective factor against HIV transmission, as reported in this and other studies ${ }^{10,11}$.

This study demonstrated that birth by vaginal delivery was associated with HIV infection in children. This corroborates several other studies that have demonstrated that childbirth by cesarean section is a protective factor ${ }^{2,9,15}$. Scheduling elective cesarean sections prevents pregnant woman from going into labor and prevents the early rupture of the amniotic membranes. 
TABLE 1 - Univariate analysis of clinical data related to HIV/AIDS diagnosis in children attending the service for specialized care for pediatric AIDS in Vitória, State of Espírito Santo, Brazil, 2005-2008 ( $\mathrm{n}=221)$.

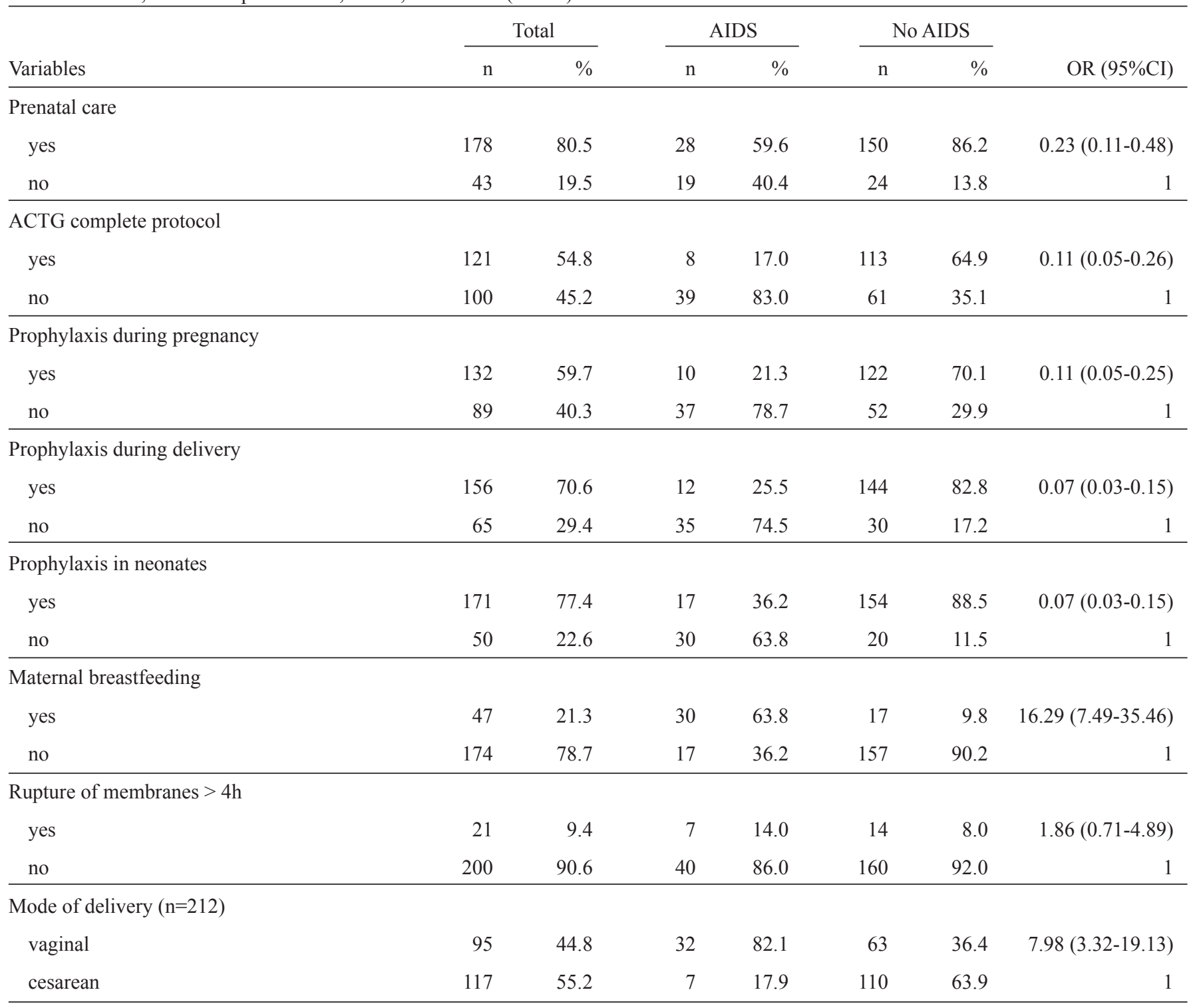

HIV: human immunodeficiency virus; AIDS: acquired immunodeficiency syndrome; OR: odds ratio; 95\%CI: 95\% confidence interval; ACTG: AIDS Clinical Trials Group.

TABLE 2 - Multivariate analysis of factors associated with HIV/AIDS diagnoses in children attending the service for specialized care for pediatric AIDS in Vitória, State of Espírito Santo, Brazil, 2005-2008 (n=221).

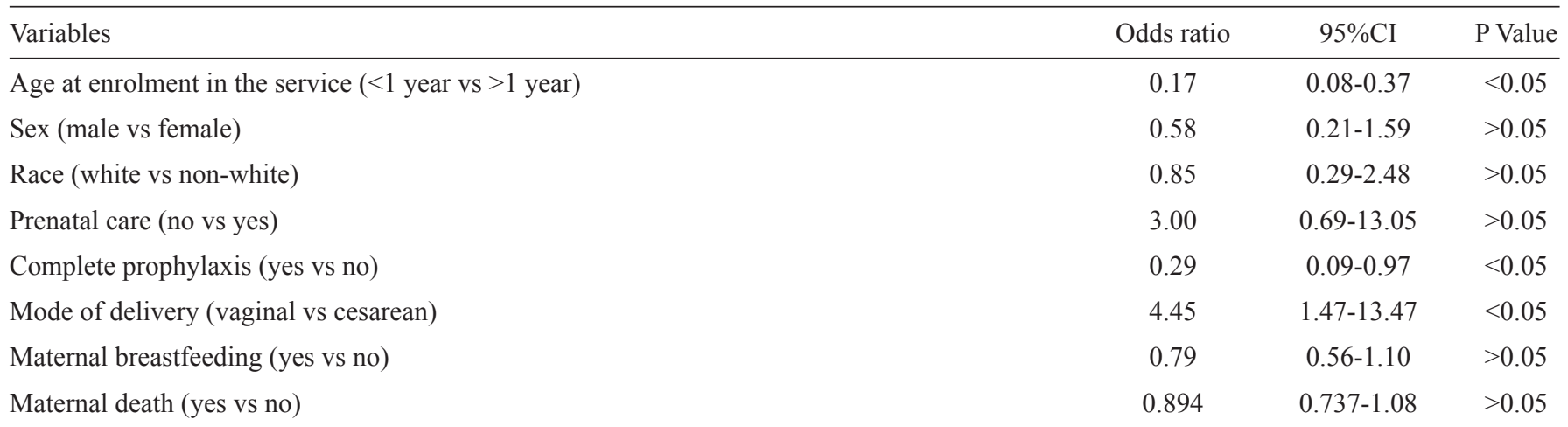

HIV: human immunodeficiency virus; AIDS: acquired immunodeficiency syndrome; 95\%CI: 95\% confidence interval; vs: versus. 
Numerous studies have shown that membrane rupture more than $4 \mathrm{~h}$ before delivery increases the risk of $\mathrm{MTCT}^{9,11}$. We did not observe this trend, likely because this information was collected secondarily, as we studied exposed children and not the pregnant women.

The HIV-infected children evaluated in this study showed moderate to severe clinical manifestations. Clinical category C3 was observed in 32\% of the infected children. The most frequent symptoms were anemia for longer than 30 days, wasting syndrome (according to the World Health Organization growth curves) and bacterial meningitis, pneumonia or sepsis. All of these clinical manifestations are considered moderate to severe for HIV infection, which correlates with the large number of patients classified in more severe clinical categories ${ }^{7}$. The manifestations of these symptoms are related to late diagnosis and delays in receiving specialized medical care.

A cross-sectional study is not the best option in assessing the frequency of HIV infection in children and the association of infection with epidemiological and clinical data, though the use of this type of study is justified for generating hypotheses. It is important to demonstrate the susceptibility of children to this route of HIV transmission to implement healthcare standards for the infected mothers and their children. The possibility of answer bias by mothers cannot be ruled out because the women might tend to give socially acceptable answers. The lack of accurate follow-up data from during pregnancy and at delivery cannot be excluded.

Children infected with HIV usually present with general signs and symptoms not specific for HIV infection. Because these signs and symptoms are so prevalent in developing countries $^{7}$, pediatric care professionals should not ignore them, as they might allow for earlier HIV diagnosis in infected children. Children who often return to healthcare centers with fever, diarrhea, recurrent infections, nonspecific lymphadenopathy and parotitis should have their medical, epidemiological and family history data rigorously collected to identify mothers who were not tested for HIV during prenatal care, other cases of siblings or other immediate family members who died with the same clinical picture and deliberate refusal of the test by the mothers for fear of discrimination or stigma ${ }^{6,7}$.

Offering free access to ART has not been completely effective in preventing MTCT in Brazil. It is also necessary to provide both adequate early prenatal care and early diagnosis of HIV infection for both the mother and the child to achieve a lower AIDS incidence in children ${ }^{8}$. The implementation of measures that have been described as effective in ensuring the reduction of MTCT should be applied by a multidisciplinary qualified team.

\section{CONFLICT OF INTEREST}

The authors declare that there is no conflict of interest.

\section{REFERENCES}

1. The Joint United Programme on HIV/AIDS (UNAIDS). AIDS epidemic update, December 2009. Geneva: UNAIDS/AIDS/World Health Organization; 2009

2. Connor EM, Sperling RS, Gelber R, Kiselev P, Scott G, O'Sullivan MJ, et al. Reduction of maternal-infant transmission of human immunodeficiency virus type 1 with zidovudine treatment. Pediatric AIDS Clinical Trials Group Protocol 076 Study Group. N Engl J Med 1994; 331: 1173-1180.

3. Ministério da Saúde, Secretaria de Vigilância em Saúde. Programa Nacional de DST e AIDS. Recomendações para Profilaxia da Transmissão Vertical do HIV e Terapia Antirretroviral em Gestantes. Série Manuais n 46. Brasília: Ministério da Saúde; 2010.

4. Ministério da Saúde, Secretaria de Vigilância em Saúde. Programa Nacional de DST e AIDS. Boletim Epidemiológico AIDS e DST. 2010, Ano VII $\mathrm{n}^{\mathrm{o}} 01-26^{\mathrm{a}}$ a $52^{\mathrm{a}}$ semanas epidemiológicas - julho a dezembro de 2009 $-01^{\mathrm{a}}$ a $26^{\mathrm{a}}$ semanas epidemiológicas - janeiro a junho de 2010. Brasília: Ministério da Saúde; 2010.

5. Bagenda D, Nassali A, Kalyesubula I, Sherman B, Drotar D, Boivin MJ, et al. Health, neurologic, and cognitive status of HIV-infected, long-surviving and antiretroviral-naive Ugandan children. Pediatrics 2006; 117:729-740.

6. Machado ARL, Silva CLO, Dutra CE, Galvão NAM. AIDS na infância: orientação básica no atendimento. J Pediatr 1994; 1:5-9.

7. Ministério da Saúde, Secretaria de Vigilância em Saúde. Programa Nacional de DST e AIDS. Recomendações para terapia antirretroviral em crianças e adolescentes infectados pelo HIV. Série Manuais $n^{\circ} 85$. Brasília: Ministerio da Saúde; 2009.

8. Nogueira SA, Abreu T, Oliveira R, Araújo L, Costa T, Andrade M, et al. Successful prevention of HIV transmission from mother to infant in Brazil using a multidisciplinary team approach. Braz J Infect Dis 2001; 5:78-86.

9. Matida LH, Ramos Jr AN, Moncau JEC, Marcopito LF, Marques HH, Succi RC, et al. Aids by mother-to-child transmission: survival analysis of cases followed from 1983 to 2002 in different regions of Brazil. Cad Saude Publica 2007; Cad Saude Publica 2007; 3:S435-S444.

10. Succi RCM, Grupo de Estudo da Sociedade Brasileira de Pediatria para Avaliar a Transmissão Materno- Infantil do HIV. Mother-to-child transmission of HIV in Brazil during the years 2000 and 2001: results of a multi-centric study. Cad Saude Publica 2007; 23:379-389.

11. Tornatore M, Gonçalves CV, Mendoza-Sassi RA, Silveira JM, D'ávila NE, Maas CG, et al. HIV-1 vertical transmission in Rio Grande, Southern Brazil. Int J STD AIDS 2010; 21:351-355.

12. Gonçalves VLMA, Troiani C, Ribeiro AA, Spir PRN, Gushiken EK, Vieira $\mathrm{RB}$, et al. Vertical transmission of HIV-1 in the western region of the State of São Paulo/Transmissão vertical do HIV-1 na região oeste do Estado de São Paulo. Rev Soc Bras Med Trop 2011; 44:4-7.

13. Soeiro CM, Miranda AE, Saraceni V, Lucena NO, Talhari S, Ferreira LC. Mother-to-child transmission of HIV infection in Manaus, State of Amazonas, Brazil. Rev Soc Bras Med Trop 2011; 44:537-541.

14. Souza Júnior PRB, Szwarcwald CL, Barbosa Júnior A, Carvalho MF, Castilho EA. Infecção pelo HIV durante a gestação: estudo-Sentinela Parturiente, Brasil, 2002. Rev. Saúde Pública 2004; 38:764-772.

15. European Collaborative Study. Mode of delivery in HIV-infected pregnant women and prevention of mother-to-child transmission: changing practices in Western Europe. 2010 British HIV Association (BHIVA) 2010; 11:368-378. 